\title{
THE EFFECT OF DIELECTRIC CONFINEMENT ON EXCITON BINDING ENERGIES IN CdS/MgS SINGLE QUANTUM WELLS
}

\author{
Chikara Onodera ${ }^{1}$, Masaaki Yoshida ${ }^{2}$ \\ ${ }^{1}$ Electronic Engineering Course, Aomori Prefectural Towada Technical Senior High School, \\ 215-1 Shimotai Sanbongi, Towada, Aomori 034-0001, Japan \\ ycd1ngt@yahoo.co.jp \\ ${ }^{2}$ Department of Electrical and Computer Engineering, Hachinohe National College of Technology, \\ 16-1 Uwanotai, Tamonoki, Hachinohe, Aomori 039-1192, Japan \\ yoshida-e@hachinohe-ct.ac.jp
}

(Received March 11, 2010)

\begin{abstract}
Binding energies of heavy- and light-hole excitons in CdS/MgS single quantum wells (SQWs) are calculated by considering the effect of dielectric confinement (image charge effect). The increase in maximum heavy-hole (light-hole) exciton binding energy calculated by considering the image charge effect is $7.7 \mathrm{meV}(5.9 \mathrm{meV})$. When the well width of the CdS/MgS SQWs is in the range of $0.5 \mathrm{~nm}-4.0 \mathrm{~nm}$ the heavy- and light-hole exciton binding energies calculated by considering the image charge effect are larger than the longitudinal optical phonon energy of CdS.
\end{abstract}

Key words: CdS, MgS, ZnS, band offset, exciton binding energy, image charge.

PACS number(s): 73.21.Fg, 78.20.Bh, 81.05.Dz

\section{INTRODUCTION}

$\mathrm{CdS} / \mathrm{ZnS}$ has a strong confinement of charge carriers and possesses strong excitonic properties which allow highly efficient luminescence at elevated temperatures [1]. However, in order to enhance these excitonic properties and achieve an even higher luminescence efficiency, particularly at room temperatures (RT), stronger confinement is necessary. Furthermore, the CdS/ZnS system has a large lattice mismatch $(7.3 \%)$. Thus, controllability of the well width of the CdS quantum well (QW) is limited by the critical thickness of CdS on ZnS. Recently, remarkable development in heteroepitaxial growth techniques have enabled the fabrication of zinc-blende $\mathrm{MgS}$ layers. The stable crystal structure of bulk MgS is a rocksalt structure [2]. Zinc-blende MgS has a bandgap of 4.8 $\mathrm{eV}$ and a lattice constant larger than that of $\mathrm{ZnS}$ [2]. Hence, zinc-blende $\mathrm{MgS}$ is an excellent barrier material for CdS QWs [2]. On the basis of the linear combination of atomic orbitals (LCAO) theory [3] the conduction and valence band offsets at the $\mathrm{CdS} / \mathrm{MgS}$ interface without induced strains are evaluated to be 1.99 and $0.25 \mathrm{eV}$, respectively. These values are larger than those in the $\mathrm{CdS} / \mathrm{ZnS}$ system (1.12 and $0.16 \mathrm{eV}$, respectively). In addition, the lattice mismatch between CdS and MgS $(3.7 \%)$ is smaller than that between CdS and $\mathrm{ZnS}$. In order to realize strong quantum confinement in QWs operating at a short wavelength, we propose the use of a CdS well combined with a MgS barrier. The exciton binding energy calculated by considering the effect of dielectric confinement (image charge effect) is larger than that calculated by neglecting the image charge effect [4]. We calculate the exciton binding energies in CdS/MgS single QWs (SQWs) by considering the image charge effect. We also calculate the exciton binding energies in CdS/ZnS SQWs by neglecting the image charge effect in order to compare them with the exciton binding energies in $\mathrm{CdS} / \mathrm{MgS}$ SQWs.

\section{CALCULATION METHODS}

Greene et al. have reported the details of the method for calculating binding energies in QWs [5]. We use a variation method for calculating the exciton binding energies. The exciton Hamiltonian is given by [5]

$$
\begin{aligned}
H=- & \frac{\hbar^{2}}{2 \mu_{ \pm}} \frac{1}{r} \frac{\partial}{\partial r} r \frac{\partial}{\partial r}-\frac{\hbar^{2}}{2 m_{e}^{*}} \frac{\partial^{2}}{\partial z_{e}^{2}}-\frac{\hbar^{2}}{2 m_{ \pm}} \frac{\partial^{2}}{\partial z_{h}^{2}} \\
& -\frac{e^{2}}{\epsilon \sqrt{r^{2}+\left(z_{e}-z_{h}\right)^{2}}} \\
& +V_{e}\left(z_{e}\right)+V_{h}\left(z_{h}\right)+V_{K T}\left(r, z_{e}, z_{h}\right),
\end{aligned}
$$

where $\mu_{ \pm}$is the exciton reduced mass and $\epsilon$, the dielectric constant. $V_{e}\left(z_{e}\right)$ and $V_{h}\left(z_{h}\right)$ are the conduction and valence band offsets, respectively. A trial function [6] is given by

$$
\varphi=\phi_{e}\left(z_{e}\right) \phi_{h}\left(z_{h}\right) \exp \left[-\alpha\left\{r^{2}+\beta\left(z_{e}-z_{h}\right)^{2}\right\}^{1 / 2}\right]
$$

where $\phi_{e}\left(z_{e}\right)$ and $\phi_{h}\left(z_{h}\right)$ are the electron and heavy-hole wave functions, respectively. $\alpha$ and $\beta$ are variational parameters.

To account for the effect of dielectric confinement on the electron-hole Coulomb interaction, we use the effective potential term $V_{\mathrm{KT}}$, as defined by Kumagai and Takagahara (KT), using the image-charge method [4]. The abovementioned expression is given in the form of an infinite series. For example, when the electrons and holes are in the well, $V_{\mathrm{KT}}$ is expressed as [7]

$$
V_{K T}=-\sum_{n=-\infty}^{\infty} \frac{\xi^{|n|}}{\epsilon_{s} \sqrt{\rho^{2}+\left(z_{e}-(-1)^{n} z_{h}+n L_{w}\right)^{2}}},
$$


where $\xi=\left(\epsilon_{s}^{w}-\epsilon_{s}^{b}\right) /\left(\epsilon_{s}^{w}+\epsilon_{s}^{b}\right)$, and $\epsilon_{s}^{w}$ and $\epsilon_{s}^{b}$ are the static dielectric constants for the well and the barrier, respectively. $L_{w}$ is the well width. Details of the method for calculating the exciton binding energies by considering the effect of image charge on the electron-hole Coulomb interaction are provided in [4].

We calculated the critical thickness of the well material $(\mathrm{CdS})$ on the barrier material $(\mathrm{MgS}$ or $\mathrm{ZnS})$ using Matthews and Blakeslee's (MB's) mechanical equilibrium model [8]. The critical thickness $h_{c}$ is given by

$$
h_{c}=\frac{b\left(1-\nu \cos ^{2} \alpha\right)}{2 \pi f(1+\nu) \cos \lambda}\left(\ln \frac{h_{c}}{b}+1\right),
$$

where $\nu$ is the Poisson's ratio; $f$, the lattice mismatch between the well and barrier; and $b$, the Burgers vector. Here, we assume that $b=\sqrt{2} a, \cos \alpha=0$, and $\cos \lambda=1$; $a$ is the lattice constant of the well material.

The conduction, heavy-hole, and light-hole band offsets have been calculated using the "model solid approach" [9]. The heavy-hole band offset is calculated as the difference between the energy at the top of the heavyhole band in the well and that in the barrier. The lighthole band offset is calculated in the same manner. The conduction band offset is calculated as the difference between the energy at the bottom of the conduction band in the well and that in the barrier. The energy at the top of the heavy-hole band in strained CdS is calculated by the summation of the energy at the top of the valence band in unstrained CdS and the energy shift of the heavy-hole band in strained CdS. The energy at the top of the light-hole band in strained CdS is calculated in the same manner. The energy at the bottom of the conduction band in strained CdS is calculated by the summation of the energy at the bottom of the conduction band in unstrained CdS and the energy shift of the conduction band in strained CdS.

The following expressions are used to describe the shift in band-edge energies with strain [2]:

$$
\begin{gathered}
\varepsilon=\frac{a_{b}-a_{w}}{a_{w}}, \\
\varepsilon_{z z}=-\frac{2 C_{12}}{C_{11}} \varepsilon, \\
E_{S}=-b\left(\varepsilon_{z z}-\varepsilon\right), \\
E_{H}=a_{v}\left(2 \varepsilon+\varepsilon_{z z}\right), \\
d E_{c}=a_{c}\left(2 \varepsilon+\varepsilon_{z z}\right), \\
d E_{h h}=E_{H}+E_{S}, \\
d E_{l h}=E_{H}-\frac{\Delta_{s o}}{2}(1+x)+\frac{\Delta_{s o}}{2}\left(1-2 x+9 x^{2}\right)^{1 / 2},
\end{gathered}
$$

where $a_{w}$ and $a_{b}$ are the lattice constants of the well and the barrier, respectively. $\varepsilon$ and $\varepsilon_{z z}$ are the strain tensors, and $C_{11}$ and $C_{12}$ are the elastic stiffness constants. $x=E_{S} / \Delta_{s o}$, where $\Delta_{s o}$ is the spin-orbit splitting energy. $a_{v}$ and $a_{c}$ are the hydrostatic deformation potentials in the valence and conduction bands, respectively, and $b$ is the shear deformation potential. The energy shifts of the conduction, heavyhole, and light-hole bands under the strain are given by eqs. (9), (10), and (11), respectively

The heavy-hole exciton transition energy is determined by subtracting the heavy-hole exciton binding energy from the effective heavy-hole bandgap energy; the effective heavy-hole bandgap energy is calculated by the summation of the minimum conduction subband energy, minimum heavy-hole subband energy, and heavy-hole bandgap energy of the well layer. The light-hole exciton transition energy is calculated in the same manner.

\section{RESULTS AND DISCUSSION}

The physical parameters used for our calculation are listed in Table I. The effective masses of heavy- and lightholes in the $z$-direction and for the $x$ - $y$ plane are determined in terms of the well-known Luttinger parameters. For simplification of our calculation, the effective masses of electrons, heavy-holes, and light-holes are assumed to be position-independent and equal to the effective masses of those of CdS.

The critical thickness of $\mathrm{CdS}$ on $\mathrm{MgS}$ is estimated to be $4.0 \mathrm{~nm}$; therefore, we calculate the heavy- and lighthole exciton binding energies in $\mathrm{CdS} / \mathrm{MgS}$ SQWs until the well width $\left(L_{w}\right)=4.0 \mathrm{~nm}$. On the other hand, the critical thickness of $\mathrm{CdS}$ on $\mathrm{ZnS}$ is estimated to be 1.5 $\mathrm{nm}$; however, we calculate the heavy- and light-hole exciton binding energies in CdS/ZnS SQWs until $L_{w}=4.0$ $\mathrm{nm}$ for the sake of comparison with those in CdS/MgS SQWs. The conduction, heavy-hole, and light-hole band offsets in CdS/MgS SQWs are 1909, 257, and $220 \mathrm{meV}$, respectively, and those in CdS/ZnS SQWs are 956, 175, and $133 \mathrm{meV}$, respectively.

Figure 1 shows heavy- and light-hole exciton binding energies in $\mathrm{CdS} / \mathrm{MgS}$ and $\mathrm{CdS} / \mathrm{ZnS}$ SQWs as functions of $L_{w}$. The heavy- and light-hole exciton binding energies calculated by neglecting the image charge effect in CdS/MgS SQWs are larger than those in CdS/ZnS SQWs; this is because the conduction and valence band offsets in CdS/MgS SQWs are much larger than those in $\mathrm{CdS} / \mathrm{ZnS}$ SQWs. The maximum heavy-hole (light-hole) exciton binding energy calculated by neglecting the image charge effect is $52.6 \mathrm{meV}(45.3 \mathrm{meV})$, whereas that calculated by considering the image charge effect is estimated to be $60.3 \mathrm{meV}(55.1 \mathrm{meV})$. Hence, the maximum heavy-hole (light-hole) exciton binding energy calculated by considering the image charge effect is $7.7 \mathrm{meV}$ (5.9 meV) larger than that calculated by neglecting the image charge effect. Changes in the binding energies of heavy- and light-hole excitons with $L_{w}$ are essentially similar. Even after considering the image charge effect, no notable change is observed in the shape of the curve obtained for the dependence of the heavy- and light-hole exciton binding energies on $L_{w}$. 


\begin{tabular}{|l|c|c|c|}
\hline & $\mathrm{CdS}$ & $\mathrm{MgS}$ & $\mathrm{ZnS}$ \\
\hline Lattice constant $(\mathrm{nm})$ & $0.5832[10]$ & $0.562[11]$ & $0.54093[10]$ \\
Bandgap energy $(\mathrm{eV})$ & $2.56[12]$ & $4.8[11]$ & $3.84[10]$ \\
Top valence-band energy $(\mathrm{eV})$ & $-11.68[3]$ & $-11.93[3]$ & $-11.84[3]$ \\
Electron effective mass & $0.173[13]$ & & \\
Luttinger parameter, $\gamma_{1}$ & $2.2[13]$ & & \\
Luttinger parameter, $\gamma_{2}$ & $0.35[13]$ & & \\
Relative dielectric constant & $8.5[13]$ & $4.506[14]$ & \\
\hline
\end{tabular}

Table 1. Physical parameters used for our calculation.

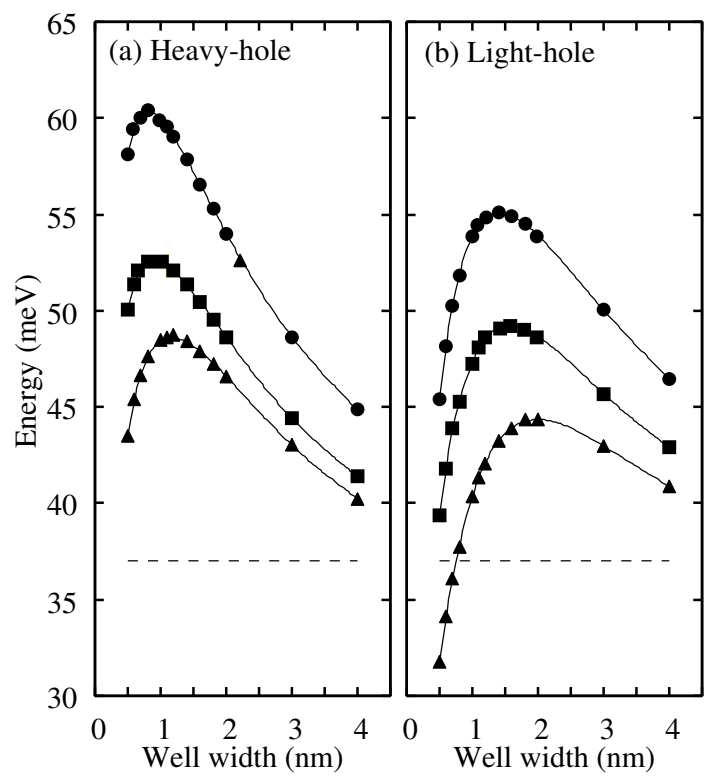

Fig. 1. Calculated (a) heavy- and (b) light-hole exciton binding energies in $\mathrm{CdS} / \mathrm{MgS}$ and $\mathrm{CdS} / \mathrm{ZnS}$ single quantum wells (SQWs) as functions of $L_{w}$. Closed triangles and squares indicate the calculated values of the exciton binding energies by neglecting the image charge effect in $\mathrm{CdS} / \mathrm{ZnS}$ and CdS/MgS SQWs, respectively. Closed circles indicate the exciton binding energies by considering the image charge effect in CdS/MgS SQWs. Solid lines serve as a visual reference. Broken lines indicate the longitudinal optical (LO) phonon energy of CdS.

The binding energy of heavy-hole excitons calculated by neglecting the quantum confinement effect $(21.0 \mathrm{meV})$ is smaller than that of light-hole excitons calculated by neglecting the quantum confinement effect $(24.6 \mathrm{meV})$. However, the maximum binding energies of heavy-hole excitons calculated by neglecting and considering the image charge effect are larger than those of light-hole excitons calculated with the same considerations. This is because the degree of compression of the exciton wave function for a heavy-hole exciton is larger than that for a light-hole exciton. In order to determine the degree of compression of the exciton wave function, we calculate the dependence of spatial separation of excitons in the $z$-direction $(\langle z\rangle)$ on $L_{w} \cdot\langle z\rangle$ is calculated using $\langle z\rangle$ $=\left\langle\varphi\left|\left(z_{e}-z_{h}\right)^{2}\right| \varphi\right\rangle^{1 / 2}[15]$. The minimum $\langle z\rangle$ for heavyhole exciton (light-hole exciton) is estimated to be 0.48 $\mathrm{nm}(0.81 \mathrm{~nm})$. The minimum $\langle z\rangle$ for heavy-hole exci- tons is smaller than that for light-hole excitons, hence, the larger degree of compression for heavy-hole excitons than that for light-hole excitons.

When the well width of the CdS/MgS SQW is in the range of $0.5-4.0 \mathrm{~nm}$, the heavy- and light-hole exciton binding energies calculated by neglecting and considering the image charge effect are all larger than the longitudinal optical (LO) phonon energy of CdS (37 meV) [16]. This indicates that the exciton characteristics are predominant even at RT. The strong interaction between the excitons and LO phonons usually results in the dissociation of the excitons at higher temperatures [17, 18]. Ionization of excitons should be prevented in system where all the excitations of the exciton have an energy larger than that of the LO phonon $[17,18]$. For a more realistic understanding of the exciton stability, the calculation of the excited exciton states is necessary. For simplification of our calculation, we discuss only the binding energy of the ground exciton state; therefore, our result is not the whole story of the exciton stability.

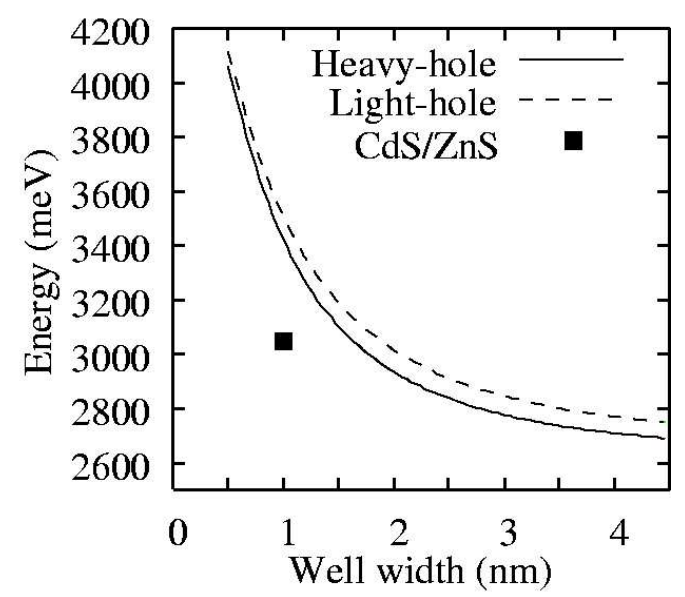

Fig. 2. Calculated heavy- and light-hole exciton transition energies in CdS/MgS SQWs as functions of $L_{w}$. The closed square indicates the measured value of $\mathrm{CdS} / \mathrm{ZnS}$ SQWs cited in [1].

Measured binding and transition energies of heavyand light-hole excitons in $\mathrm{CdS} / \mathrm{MgS}$ SQWs are not available at present. In order to compare the theoretical results with the experimental results, we use the energy of the exciton transition measured by experiment for $\mathrm{CdS} / \mathrm{ZnS}$ SQWs [1] because the well layer of this SQWs 
consists of a CdS. We calculate the heavy- and lighthole exciton transition energies by considering the image charge effect in CdS/MgS SQWs. Figure 2 shows the calculated results; whereas the closed square indicates the measured value of CdS/ZnS SQWs cited in [1]. The heavy- and light-hole exciton transition energies calculated by considering the image charge effect are larger than the measured value of the same for CdS/ZnS SQWs; this is because the bandgap discontinuity between $\mathrm{CdS}$ and $\mathrm{MgS}$ is larger than that between CdS and $\mathrm{ZnS}$.

\section{SUMMARY}

We have calculated the binding energies of heavy- and light-hole excitons in CdS/MgS SQWs by considering the image charge effect. The maximum binding energy of the heavy-hole (light-hole) exciton calculated by considering the image charge effect is $60.3 \mathrm{meV}$ ( $55.1 \mathrm{meV})$. The increase in the maximum binding energy of the heavy-hole (light-hole) exciton calculated by considering the image charge effect is $7.7 \mathrm{meV}(5.9 \mathrm{meV})$. The dependence of heavy-hole and light-hole exciton binding energies calculated by considering the image charge effect on $L_{w}$ is qualitatively the same as that by neglecting the image charge effect. When the well width of the CdS/MgS SQWs is in the range of $0.5 \mathrm{~nm}-4.0 \mathrm{~nm}$, the heavy- and light-hole exciton binding energies are larger than the LO phonon energy of CdS. The heavy- and light-hole exciton transition energies calculated by considering the image charge effect are larger than the measured value of the same for CdS/ZnS SQWs. Therefore, CdS/MgS SQWs can be used for the fabrication of ultraviolet applications based on RT exciton transition.
[1] U. Woggon, W. Petri, A. Dinger, S. Petillon, M. Hetterich, M. Grün, K. P. O’Donnell, H. Kalt, C. Klingshirn, Phys. Rev. B 55, 1364 (1997).

[2] B. Urbaszek, C. M. Townsley, X. Tang, C. Morhain, A. Balocchi, K. A. Prior, R. J. Nicholas, B. C. Cavenett, Phys. Rev. B 64, 155321 (2001).

[3] W. A. Harrison, Elementary Electronic Structures (World Scientific, Singapore, 2004), revised edition, p. 676 .

[4] M. Kumagai, T. Takagahara, Phys. Rev. B 40, 12359 (1989).

[5] R. L. Greene, K. K. Bajaj, D. E. Phelps, Phys. Rev. B 29, 1807 (1984).

[6] R. T. Senger, K. K. Bajaj, Phys. Rev. B 68, 205314 (2003).

[7] R. Zheng, M. Matsuura, Phys. Rev. B 58, 10769 (1998).

[8] J. W. Matthews, A. E. Blakeslee, J. Cryst. Growth 27, 118 (1974).

[9] K. Shahzad, D. Olego, C. G. van de Walle, Phys. Rev. B 38, 1417 (1988).

[10] Y. Yamada, in: Optical Properties of Low-dimensional Materials, Eds. T. Ogawa and Y. Kanemitsu (World Sci- entific, Singapore, 1995), Chap. 4.

[11] M. Funato, K. Omae, Y. Kawakami, Sg. Fujita, C. Bradford, A. Balocchi, K. A. Prior, B. C. Cavenett, Phys. Rev. B 73, 245308 (2006).

[12] J. T. Mullins, T. Taguchi, P. D. Brown, Y. Y. Loginov, K. Durose, Jpn. J. Appl. Phys. 30, L1853 (1991).

[13] Z. G. Yu, C. E. Pryor, W. H. Lau, M. A. Berding, D. B. MacQueen, J. Phys. Chem. B 109, 22913 (2005).

[14] F. Drief, A. Tadjer, D. Mesri, H. Aourag, Catal. Today 89, 343 (2004).

[15] Y. Shinozuka, M. Matsuura, Phys. Rev. B 28, 4878 (1983) [Errata; 29, 3717 (1984)].

[16] Y. Kanemitsu, T. Nagai, Y. Yamada, T. Taguchi, Appl. Phys. Lett. 82, 388 (2003).

[17] B. Urbaszek, C. M. Townsley, X. Tang, C. Morhain, A. Balocchi, K. A. Prior, R. J. Nicholas, B. C. Cavenett, Phys. Rev. B 64, 155321 (2001).

[18] B. Urbaszek, C. Morhain, C. Bradford, C. B. O'Donnell, S. A. Telfer, X. Tang, A. Balocchi, K. A. Prior, B. C. Cavenett, C. M. Townsley, R. J. Nicholas, J. Phys.: Condens. Matter 13, 2317 (2001).

\title{
ВПЛИВ ДІЕЛЕКТРИЧНОГО ОТОЧЕННЯ НА ЕНЕРГІЇ ЗВ'ЯЗКУ ЕКСИТОНІВ У КВАНТОВИХ ЯМАХ СИСТЕМ CdS/MgS
}

\author{
Чікара Онодера ${ }^{1}$, Масаакі Йошіда ${ }^{2}$ \\ ${ }^{1}$ Технічна старша середня школа м. Товада, префектура Аоморі, Японія \\ ${ }^{2}$ Національний технічний коледж м. Гачіноге, префектура Аоморі, Японія
}

\begin{abstract}
Енергї зв'язку важких і легких екситонів у квантових ямах кристалів CdS/MgS обчислено з урахуванням ефекту діелектричного оточення, який приводить до зростання максимуму на 7.7 меВ (випадок важких дірок) і 5.9 меВ (випадок легких дірок). Для ширин ями 0.5-4.0 нм обчислені енергї̈ зв'язку більші за енергії поздовжніх оптичних фононів у CdS.
\end{abstract}

